\title{
PESQUISA, LEITURA E ESCRITA NO ENSINO SUPERIOR: UMA ANÁLISE DE MONOGRAFIAS PRODUZIDAS NO ISCED DO SUMBE-ANGOLA*
}

\section{RESEARCH, READING AND WRITING IN HIGHER EDUCATION: AN ANALYSIS OF MONOGRAPHS PRODUCED AT ISCED IN SUMBE-ANGOLA}

\author{
Belarmino Simão Proença Justino** \\ Marinalva Vieira Barbosa ${ }^{* * *}$ \\ Lourenço Lino de Sousa ${ }^{* * * *}$
}

\begin{abstract}
RESUMO: Este artigo tem como objetivo apresentar uma análise de produções escritas de alunos de cursos de licenciaturas do Instituto Superior de Educação do Sumbe - ISCED, visando descrever a construção linguística dos trabalhos do fim de curso (TFC), no gênero monografia. O estudo do corpus teve como base as concepções apresentadas Marconi e Lakatos (2003), Severino (2007) e Zinga, Camaraza e Sakongo (2019). Trata-se de uma pesquisa qualitativa, descritiva e documental porque tem como foco as características observáveis e gerais sobre como são construídas as monografias. Para composição do corpus analisado neste artigo, foram selecionadas 02 (duas) monografias concluídas no ano de 2018, em dois cursos do ISCED. A pesquisa demonstrou que, a partir da interpretação das orientações para escrita de monografias no ISCED, os concluintes dos cursos tendem a produzir uma escrita homogênea, semelhante entre si, independente da área de conhecimento e tema abordados. Ou seja, o que se identificou foi uma escrita com características sintática, semânticas e analíticas fortemente parafrásticas.
\end{abstract}

Palavras-chave: Escrita; Monografia; Licencituras; Angola.

ABSTRACT: This article aims to present an analysis of the written productions of undergraduate students at the Cuanza Sul Higher Institute of Education - ISCED, in

Os dados analisados neste artigo fazem parte de uma pesquisa desenvolvida para escrita da dissertação de mestrado do primeiro autor, sob a orientação da segunda autora, e que integra o projeto intitulado "Leitura e escrita no Brasil, Honduras, Angola e Chile: formação na universidade contemporânea e (re)produção de conhecimento". Esse projeto maior visa problematizar a relação entre leitura, escrita e produção de conhecimento na universidade contemporânea em diversas áreas do conhecimento.

** Mestre em Ciências da Educação. Especialização Ensino da Língua Portuguesa pelo ISCED do Sumbe (Angola). Contato: belarmino28justino@gmail.com

*** Doutora em Linguística pela UNICAMP. Professora da Universidade Federal do Triângulo Mineiro (UFTM), Departamento de Linguística e Língua Portuguesa. Contato: marinalvav@gmail.com

${ }^{* * * *}$ Doutor em Ciência Animal. Docente e Coordenador da Comissão Instaladora do ISCED do Sumbe, Cuanza Sul (Angola). Contato: Ildesousa@hotmail.com 
order to describe the linguistic construction of the final work of the course (FWC), in the monograph genre. The corpus of the study was based on the concepts presented by Marconi and Lakatos (2003), Severino (2007) and Zinga, Camaraza and Sakongo (2019). It is a qualitative, descriptive and documentary research because it focuses on the observable and general characteristics of how the monographs are constructed. To compose the corpus analyzed in this article, 02 (two) monographs completed in 2018, in two ISCED courses, were selected. The research showed that, based on the interpretation of the guidelines for writing monographs at ISCED, course graduates tend to produce a homogeneous writing, similar to each other, regardless of the area of the study and topic addressed. In other words, it was identified a strongly paraphrastic writing as for syntactic, semantic and analytical characteristics.

Keywords: Writing; Monography; Degrees; Angola.

\section{INTRODUÇÃO}

A universidade é o lugar de formação qualificada de recursos humanos para atender às diferentes demandas de um país. A qualidade dessa formação define a qualidade e a força do desenvolvimento e crescimento de um país mediante das exigências do século XXI de que a educação seja responsável pela formação de cidadãos que consigam responder às demandas profissionais concernentes ao campo de formação. É nesta perspectiva que o governo angolano define, na Lei de Base do Sistema de Educação e Ensino (LBSEE32/20), no seu artigo 65, pontos 1 e 2, que "O ensino universitário é orientado para as formações científicas sólidas, com ações de formação aliadas à investigação científica fundamental, tendo em consideração as necessidades específicas de desenvolvimento do país e é ministrado nas Academias de Altos Estudos, Universidades, Institutos Superiores Universitários, e Escolas Superiores Universitárias".(p.5)

A pesquisa acadêmica é parte fundamental dessa formação e, principalmente, para a produção de conhecimentos. Formação de qualidade e produção de conhecimentos exigem proficiências consistentes em leitura e escrita. Por essa perspectiva, a educação universitária será bem-sucedida se promover a formação de indivíduos que, ao dialogarem com o conhecimento que lhes é dado a ler, produzam novos conhecimentos ao escrever seus próprios textos. Assim, o foco central do ensino deve voltar-se para a construção de meios para que aqueles que aprendem também elaborem compreensões próprias sobre os objetos de aprendizagem. Nesse movimento, 
são criadas as condições para que a aprendizagem se transforme em um processo de criação e não de repetição do conhecimento já produzido em outros espaços e tempos.

Em Angola, as problemáticas relacionadas ao ensino e aprendizagem da leitura e escrita são maiores por causa do passado histórico-social decorrente da guerra que assolou o país. Gerações inteiras, por causa do conflito, ficaram fora da escola ou então tiveram uma escolarização precária. Soma-se a isso a situação de pobreza e desigualdade a que estão submetidas parcelas importantes da população. Essa população tem trazido para as instâncias governamentais e educacionais importantes demandas e desafios no que diz respeito ao direito e acesso à uma educação de qualidade.

Mediante esse contexto histórico e socioeconômico, estudos têm demonstrado que em Angola muitos estudantes chegam a terminar o ensino superior sem domínio consistente da leitura e escrita. Muitos sequer sabem como elaborar o trabalho de conclusão de curso. A razão dessa dificuldade remonta a deficiências e dificuldades que veem dos níveis anteriores de escolarização. Há, neste caso, um ciclo que se mantém, uma vez que os estudantes angolanos chegam à universidade com fraco domínio da leitura e escrita e, por conseguinte, nessa etapa, o problema persiste. Isso ocorre porque, muitas vezes, as disciplinas voltadas para o ensino da leitura e escrita ficam restritas ao ensino das vertentes teóricas e metodológicas sobre como fazer um trabalho científico, sem que cheguem ao foco do ensino universitário, que é a produção de novos conhecimentos, por meio da leitura e escrita.

Foi considerando essa complexa situação, perceptível no cotidiano de trabalho de professores e alunos do ISCED do Sumbe, que surgiram as questões de base da pesquisa que sustenta as reflexões desenvolvidas neste artigo. São elas: como se materializam na elaboração de trabalhos de conclusão de curso (TCC) dos estudantes do ISCED do Sumbe as dificuldades de leitura e escrita?

Para responder a essa questão, neste artigo, analisaremos 02 (duas) monografias produzidas, no ano de 2018, em dois diferentes cursos de licenciaturas do ISCED. Serão analisadas, nessas duas produções, a construção sintática e semântica dos temas, problemas e objetivos de 
pesquisa; também será analisada a escrita das concepções metodológicas e das formas de citação de outros autores, ou seja, neste último caso, o foco das análises recai sobre como se dá o trabalho com a palavra do outro.

No desenvolvimento das descrições analíticas, assumimos a compreensão de que a escrita e a leitura, decorrentes do ato de estudarpesquisar, são de fundamental importância para a formação e, principalmente, para a produção de conhecimento na universidade contemporânea. Assim, à luz das concepções defendidas por Marconi e Lakatos (2003), Severino (2007) e Zinga, Camaraza e Sakongo (2019), analisaremos a forma de escrita das monografias que compõem o corpus da pesquisa.

\section{CONTEXTO DE DESENVOLVIMENTO DA PESQUISA}

O Instituto Superior de Ciências da Educação do Sumbe (ISCED) inicialmente fazia parte do Polo Universitário do Cuanza Sul, criado em 1999, pertencente à Universidade Agostinho Neto, única universidade pública à época. Com o redimensionamento da Universidade Agostinho Neto e o consequente surgimento das regiões académicas, em 2009, o Cuanza Sul foi inserido na Região Académica II, sob a égide da Universidade Katyavala Bwila (UKB), com sede em Benguela. Foi deste modo que o Polo Universitário se transformou em Instituto Superior de Ciências da Educação do Cuanza Sul (ISCED-CS) como uma das Unidades Orgânicas da UKB.

As atividades letivas do ISCED foram iniciadas com 107 estudantes distribuídos nos cursos de licenciatura em ensino da Pedagogia e ensino da Psicologia (em 2001), tendo posteriormente iniciados os cursos de ensino da História, Matemática e Geografia (2002 e 2003) respectivamente. Em 2018, iniciaram os cursos de licenciatura em Ensino da Química e de Sociologia; em 2020 teve início o curso de Ensino da Língua Portuguesa. Atualmente, o ISCED oferece oito cursos de licenciaturas. Oferece também três cursos de mestrado: Mestrado em Educação Pré-Escolar; Mestrado em Ensino Primário e Mestrado em Ciências da Educação, contemplando este último quatro especializações: Ensino da Matemática, Ensino de Língua portuguesa, Ensino de Geografia e Ensino de História. 
A Instituição tem neste momento um universo de 2.170 estudantes matriculados nos cursos de licenciatura e 162 nos cursos de pós-graduação (mestrandos). O quadro docente é constituído por 12 doutores, 21 mestres e 13 licenciados, perfazendo um total de 46 docentes efetivos.

Tendo em vista que o Sumbe é a capital da Província do Cuanza Sul e por ser uma das duas únicas IES públicas, a outra é o Instituto Superior Politécnico do Cuanza Sul (ISP CS), o ISCED recebe alunos oriundos dos outros onze municípios da província, isto é, Amboim, Conda, Cassongue, Ebo, Kibala, Libolo, Mussende, Porto-Amboim, Quilenda, Seles,Waco-Kungo e ainda uma menor parte vindo de outras províncias do país. Na instituição, encontramse estudantes jovens, tal como diz a Constituição da República de Angola (CRA), no seu Artigo 24: considera-se Juventude como a fase que começa aos 18 anos de idade. São aqueles estudantes que frequentaram o II Ciclo do Ensino Secundário nos liceus, que vão apenas até a $12^{\underline{a}}$ classe, e que nunca reprovaram. Por isso, prestam seleção para ingresso nos cursos do ISCED imediatamente após o término da educação básica, começando assim o ensino superior com 18 anos de idade. Adultos e até idosos formam uma pequena parte desse alunado, principalmente no ensino pós-laboral que se realiza no período noturno.

Sendo assim, os estudantes se dividem entre trabalhadores e não trabalhadores, estes últimos são a maior parte. Entre os trabalhadores, a maior parte é professor da educação básica angolana; a outra parte trabalha nas distintas áreas do setor produtivo da província em particular e em Angola no geral. Os não trabalhadores são dependentes dos seus encarregados de educação, outros vivem por conta própria. Existem alguns estudantes, um pequeno número, que recebem bolsas do Instituto Nacional de Gestão de Bolsa de Estudo (INAGBE). Além da dificuldade em manter os estudos e alimentação, os estudantes oriundos dos municípios do interior e de outras províncias vizinhas, precisam ainda alugar habitações para viver ou habitar com familiares ou amigos.

No ISCED, existem estudantes que apresentam capacidade financeira para suportar os encargos que acarretam a formação no nível superior, outros têm poucas condições financeiras, o que, muitas vezes, os obriga arranjarem 
mecanismos para suportar os custos da formação universitária, tais como pequenos negócios ambulantes, entre outras formas. Diante disso, alguns acabam desistindo dos cursos, principalmente os dos período pós-laboral. Isso ocorre porque, mesmo sendo o ISCED uma instituição pública, são cobradas taxas dos estudantes. Ou seja, como os cursos ministrados no regime póslaboral não têm suporte direto do Orçamento Geral do Estado (OGE), os encargos cobrados dos estudantes, por exemplo, são usados para remuneração dos recursos humanos envolvidos.

Entre os estudantes do ISCED existem também os que são trabalhadores oriundos dos outros municípios. Esses intercalam o trabalho com a formação, isto é, semana de trabalho e semana de formação, ou ainda, alguns dias de trabalho outros dias de estudo. Muitas vezes, essa situação faz com que esses estudantes consigam conciliar tempo de estudos e tempo de trabalho por causa da pressão que os responsáveis pelas instituições que trabalham fazem pela permanência nos locais de trabalho. Em contrapartida, o regime acadêmico do ISCED do Sumbe estabelece o regime presencial na formação. Consequentemente, alguns estudantes têm que optar por trabalhar ou apenas estudar, uma vez que, quando estão a estudar, abandonam o trabalho e quando estão a trabalhar perdem aulas e até avaliações ou provas.

Em suma, é considerando o contexto da educação angolana, afetado seriamente pelos conflitos que ocorreram no país, e a atual realidade dos estudantes que a escrita precisa ser pensada como elemento constitutivo da formação inicial. Ou seja, a formação universitária em Angola passa também centralmente pela escrita. Portanto, os impactos do contexto histórico, político e econômico do país afetam de forma contundente nos modos como essa formação vem sendo trabalhada e, principalmente, impacta no modo como os estudantes se relacionam com a escrita e a produção de conhecimento.

\section{ESCRITA, FORMAÇÃO UNIVERSITÁRIA E PRODUÇÃO DE CONHECIMENTO}

A formação universitária se faz por meio de uma intensa relação com a escrita. Ou seja, é uma formação centrada no ato de ler e escrever. No entanto, Severino (2007) assinala que a produção do texto tem sido precária. Há um 
não saber que cada vez mais vem se tornando presente nessa etapa de formação. Diante disso, de modo imediato essa precariedade é explicada pela dificuldade que os alunos contemporâneos encontram para redigir um bom texto. Dito de outro modo, seria o resultado da dificuldade de manusear a língua portuguesa de modo a construir um texto coerente. Entretanto, Severino destaca que a precariedade do escrever no âmbito do processo formativo da universidade tem causa mais profunda do que a falta de domínio redacional. Mais do que técnico, o problema é lógico, a dificuldade em bem escrever deriva das limitações no pensar atualmente (SEVERINO, 2007).

Severino enfatiza que essa dificuldade decorre do modelo de formação vigente na universidade. Na tradição cultural brasileira, que têm relação com as tradições formativas vigentes no mundo contemporâneo, entende-se a universidade como lugar de ensino, sobretudo, praticado como transmissão de conhecimentos. Essa, de fato, é uma tradição do modelo que universidade que ganhou preponderância no mundo ocidental e que chega ao mundo africano. Essa tradição levou a produção de sujeito de aprendizagem passivo, que antes é ensinado a ouvir, preferencialmente sem muito questionar, tudo aquilo que Ihe é apresentado na forma de conhecimentos produzidos pelas gerações anteriores. Essa escuta passiva, desvinculada do questionar tal como é feito por meio da pesquisa, gera uma dificuldade no que diz respeito a construção da relação entre escrever, pensar, relacionar, interpretar e produzir conhecimentos.

A desvinculação entre ensino e pesquisa na formação inicial tem impacto no modo como se constitui o trabalho com a escrita na universidade e consequentemente na produção de conhecimento, uma vez que, de modo geral, a educação universitária pode ser conceituada como o processo mediante o qual o conhecimento se produz, se reproduz, se conserva, se sistematiza, se organiza, se transmite e se universaliza o conhecimento. Para que esse processo se efetive, é necessário que a educação universitária seja pautada por uma formação que, desde o seu momento inicial, seja pautada pelo aprendizado da pesquisa (SEVERINO, 2007). Por meio dela, a escrita assume papel de uma prática não somente obrigatória, produzida por meio de tarefas que visam o cumprimento das obrigações decorrentes da formação, 
mas numa prática que de fato é impulsionada pela vontade de saber lastreada no ato de perguntar, questionar.

Ou seja, de acordo com Severino (2007) só se aprende, só se ensina, pesquisando, só se presta serviço à comunidade se tais serviços nascerem e se nutrirem da pesquisa. $O$ professor precisa da prática da pesquisa para ensinar, o aluno precisa dela para aprender de forma significativa. A comunidade precisa da pesquisa para poder dispor de produtos do conhecimento e a universidade precisa da pesquisa para ser mediadora da educação. A pesquisa é coextensiva a todo o tecido da instituição universitária: ela aí se desenvolve capilarmente. Ensino e pesquisa precisam ser organizados no interior da universidade como práticas fundamentais ao processo de formação e produção de conhecimento.

Por essa perspectiva, a formação universitária não pode ser vista, desde o seu momento inicial, como ato de repassar conhecimento. O acesso ao conhecimento produzido pelas gerações anteriores precisa ocorrer lastrado na ideia de que o aluno universitário precisa se relacionar com essa herança buscando produzir outros conhecimentos. Ou seja, a sua relação precisa se constituir com base em inquietações e perguntas.

\section{A MONOGRAFIA COMO PRODUÇÃO ACADÊMICA DE CONCLUSÃO DE CURSO DE GRADUAÇÃO}

Para Severino (2007), monografia é um gênero acadêmico que aborda tema e problemas únicos. Ou seja, a monografia "caracteriza-se mais pela unidade e delimitação do tema e pela profundidade do tratamento do que por sua eventual extensão, generalidade ou valor didático" (SEVERINO, 2007, p.200).

Marconi e Lakatos (2003) complementam a perspectiva de Severino ao afirmarem que a monografia tem como base a escolha de uma unidade ou elemento social, sob duas circunstâncias: 1-) Ser suficientemente representativo de um todo cujas características se analisa; 2-) Ser capaz de reunir os elementos constitutivos de um sistema social ou de refletir as incidências e fenómenos de carácter autenticamente coletivo. As autoras afirmam ainda que 
A característica essencial da monografia não é a extensão, como querem alguns autores, mas o carácter do trabalho (tratamento de um tema delimitado) e a qualidade da tarefa, isto é, o nível da pesquisa, que está íntimamente ligado aos objectivos propostos para a elaboração [..] A monografia implica originalidade, mas até certo ponto, uma vez que é impossível obter total novidade em um trabalho, isto é relativo, pois a ciência sendo acumulativa, está sujeita a contínuas revisões (MARCONI; LAKATOS, 2003, p.235).

$\mathrm{Na}$ universidade (nos cursos de graduação), espera-se do aluno a produção de uma monografia a partir de um tema específico e com uma abordagem não muito abrangente. Isso porque o aluno, nesse nível acadêmico, ainda não tem formação suficiente para produzir conhecimento sobre um tema de forma profunda e com total originalidade. Trata-se muito mais de uma produção que visa levar o aluno, ao final de sua trajetória inicial de formação a produzir uma reflexão sobre um tema da sua área de formação, que ateste como, ao longo do curso, construiu a sua relação com os conhecimentos e, principalmente, que demonstre capacidade de questionamento e de produção de reflexão crítica.

No texto de apoio da Unidade Curricular de Metodologia de Investigação Educativa do ISCED, Zinga, Camaraza e Sakongo (2019) afirmam que a palavra monografia remete a um estudo por escrito de um só tema, bem delimitado, estudado exaustivamente. Os autores enfatizam que, de modo geral, uma monografia consiste em um trabalho científico para obtenção do grau de licenciado e deve apresentar como característica a originalidade, não no sentido da absoluta novidade, mas no sentido de tratar um tema relevante e que, por isso, merece ser investigado. Outra característica que deve ser considerada, conforme os autores mencionados, é a reflexão. Sem esta, o trabalho monográfico se transforma em simples compilação de obras de autores sobre o tema estudado.

Segundo o Artigo 10ำ do Regulamento dos Trabalhos de Fim de Curso (RTFC) do ISCED, a monografia é um trabalho científico sobre um determinado tema e deve ser elaborada sob a orientação de um docente com o grau acadêmico de doutor ou mestre. É realizada tendo em vista a necessidade de que, no decorrer da formação inicial, seja posta para os estudantes a 
possibilidade de desenvolvimento da pesquisa, sob proposta fundamentada do docente/regente/coordenador, sem prejuízo de escolha do estudante.

\section{A CONSTRUÇÃO DO CORPUS DA PESQUISA}

O corpus analisado neste artigo foi construído com base na concepção de pesquisa qualitativa. Marconi e Lakatos (2003, p. 269) afirmam que "a metodologia qualitativa se preocupa em analisar e interpretar aspectos mais profundos, descrevendo a complexidade sobre as investigações, hábitos, atitudes, tendências de comportamentos etc." Ou seja, neste caso, trata-se de uma pesquisa que tem como objetivo a interpretação e compreensão da realidade da escrita da monografia produzidos em cursos de graduação do ISCED do Sumbe.

O ISCED do Sumbe é composto por 08 cursos de licenciaturas que estão distribuídos entre os seguintes departamentos: O Departamento de Ciências de Educação, alberga os cursos de Ensino da Pedagogia e Ensino da Psicologia, o Departamento de Ciências Exatas, alberga os cursos de Ensino da Matemática e Ensino da Química, o Departamento de Ciências Sociais, alberga os cursos de Ensino da História e Ensino da Sociologia, o Departamento de Ciências da Natureza, alberga o curso de Ensino da Geografia e o Departamento de Letras Modernas, alberga o curso de Ensino da Língua Portuguesa.

Para o desenvolvimento da pesquisa maior, selecionamos 10 trabalhos conclusivos, concluídos no ano de 2018, sendo 02 de cada um dos cursos existentes e que já têm trabalhos defendidos. Os cursos de Química, Sociologia e Língua Portuguesa ainda não têm trabalhos conclusivos. Essa seleção se justifica porque permite realizar um estudo a partir da análise de trabalhos de todos os cursos com trabalhos defendidos, que estão divididos entre as seguintes áreas do conhecimento: Ciências de Educação; Ciências Exatas, Ciências Sociais e Ciências da Natureza. Neste artigo, analisaremos 02 (dois) trabalhos monográficos conclusivos (C1M1 e C2M2), ambos pertencentes ao departamento de Ciências de Educação. 
No que fiz respeito à definição de trabalho de conclusão, consideramos o gênero monografia, em detrimento do gênero aula ${ }^{1}$ ou outra forma de conclusão do curso que porventura vem sendo realizada no ISCED. A opção pela monografia se justifica por ser uma modalidade universalmente utilizada para a finalização da graduação ou licenciatura em qualquer país, é organizada a partir de uma questão de pesquisa e tem a escrita como principal forma de desenvolvimento.

As monografias selecionadas para análise neste artigo, assim como as que compõem o corpus maior, foram identificadas da seguinte maneira: curso 01 (um), monografia 01 (um) (C1M1), que corresponde ao curso 1 (C1) e monografia 1 (M1) em análise desse curso; curso 02 (dois), monografia dois (C2M2), que corresponde ao segundo curso e primeira monografia desse curso em análise; curso dois, monografia um (C2M2). Essa forma de identificação foi construída considerando a necessidade de preservar as identidades dos autores e dos cursos em que foram produzidas, embora, quando tratamos dos temas das monografias, as áreas do conhecimento a que pertencem são geralmente mencionadas.

\section{CONCEPÇÕES E TECITURA DA ESCRITA NAS MONOGRAFIAS}

A construção sintática e semântica dos temas, problemas e objetivos

A sintaxe da língua portuguesa está relacionada aos aspectos estruturais e formais da língua. De acordo com a Gramática Moderna da Língua Portuguesa de Ribeiro, et al (2012), a sintaxe é a área da linguística que tem como objeto de estudo a frase. Ou seja, trata-se do estudo acerca da forma como as palavras se combinam para formarem frases. "A frase é um enunciado de sentido completo, unidade mínima de construção, que pode ser construída por uma única oração (frases simples), por mais do que uma oração

\footnotetext{
${ }^{1}$ Gênero de trabalho de conclusão de curso em que o concluinte escolhe um tema específico de uma disciplina curricular do curso em que está sendo formado. $\mathrm{Na}$ aula, o concluinte precisa fundamentar os aspectos didáticos-pedagógicos e científico acerca de como ministraria a aula sobre o tema escolhido.
} 
(frases compostas) ou apenas por um verbo (frase elíptica, estando os restantes constituintes submetidos)". (RIBEIRO, et. al, 2012, p. 221).

A semântica está relacionada ao estudo do significado dos vocábulos e estruturas frasais da língua portuguesa. Podemos até conhecer a estrutura de uma palavra ou frase, mas é necessário considerarmos também seus aspectos semânticos, sem isso não é possível entender o seu significado. Nesse sentido, a forma de construção sintática de uma frase/oração/período é determinante para a construção dos sentidos. O inverso também é necessário considerar, uma vez que os sentidos que se busca produzir em um texto exigem daquele que escreve a consideração acerca de qual construção sintática recorrer.

Diante disso, torna-se relevante analisar como são organizadas as estruturas sintáticas dos temas, objetivos e problemas nas monografias selecionadas para este estudo. Importa também analisar os significados que tais construções produzem considerando as definições metodológicas comumente apresentadas para cada um desses termos. Procuraremos descrever como temas, objetivos e problemas foram elaborados e quais relações (de complementaridade, disjunção ou repetição) estabelecem entre si em C1M1 e C2M2.

\section{C1M1}

\begin{tabular}{|c|c|}
\hline Assunto & O processo de desenvolvimento da habilidade de leitura \\
\hline Tema & $\begin{array}{l}\text { Acções para o desenvolvimento a habilidade de leitura nos } \\
\text { alunos da } 4 \text { a classe na escola do Ensino Primário 411, } \\
\text { Município do Sumbe/2018 }\end{array}$ \\
\hline Problema & $\begin{array}{l}\text { Qual é o estado do desenvolvimento da habilidade de leitura } \\
\text { nos alunos da } 4^{a} \text { classe da Escola Primária } 411 \text { do Sumbe? }\end{array}$ \\
\hline Hipótese & Não há \\
\hline $\begin{array}{l}\text { Objectivo } \\
\text { geral }\end{array}$ & $\begin{array}{l}\text { Analisar o estado actual de desenvolvimento da habilidade de } \\
\text { leitura nos alunos da } 4^{a} \text { classe da escola primária } 411 / \text { sumbe } \\
\text { do Sumbe. }\end{array}$ \\
\hline $\begin{array}{l}\text { Objectivos } \\
\text { Específicos }\end{array}$ & $\begin{array}{l}\text { 1- Determinar os fundamentos teóricos que se relacionam com } \\
\text { o desenvolvimento da habilidade diagnosticada de leitura nos } \\
\text { alunos. } \\
\text { 2- Identificar os factores que estão na base das dificuldades } \\
\text { de aprendizagem da leitura por parte dos alunos da } 4^{a} \text { classe } \\
\text { da Escola Primária } 411 \text {, do Sumbe. }\end{array}$ \\
\hline
\end{tabular}


Em C1M1, o tema está assim circunscrito: Acções para 0 desenvolvimento a habilidade de leitura nos alunos da $4^{\underline{a}}$ classe na escola do Ensino Primário 411, Município do Sumbe/2018. Em uma primeira leitura, o termo "ações para o desenvolvimento" retira o caráter de pesquisa e a transforma em uma proposta de extensão. Ou seja, o tema não demarca uma questão, mas uma ação. Se a hipótese do leitor for a de que a proposta de pesquisa visa estudar as ações que estão sendo desenvolvidas visando o ensino da leitura, isso não se sustenta no conjunto de enunciados que compõe o tema, problema e objetivos.

O problema, que precisa ter relação com o tema e, ao mesmo tempo, explicá-lo, está posto da seguinte forma: Qual é o estado do desenvolvimento da habilidade de leitura nos alunos da $4^{a}$ classe da Escola Primária 411 do Sumbe? Aqui o foco do enunciado não são as ações para o desenvolvimento, mas sim o estado do desenvolvimento da habilidade de leitura. Entre assunto, tema e problema, temos três termos que podem apontar para sentidos diferentes: processo, ações e estado. São tópicos diferentes. Da perspectiva semântica, estudar as ações dá a ideia de que o que interessa são as estratégias usadas para promover o desenvolvimento da leitura, portanto o foco seria o ensino da leitura. Já um estudo do estado atual do desenvolvimento da leitura, da perspectiva semântica, remete a um estudo do nível de aprendizagem dos alunos. Ou seja, seria uma análise acerca de como os alunos estão aprendendo a ler. O processo, seria o estudo dos percursos do ensino e aprendizagem da leitura. Nesse sentido, assunto, tema e problema apontam para questões diferentes, não complementares.

No que diz respeito à construção sintática e semântica do tema e do objetivo geral, há uma relação de repetição, visto que em ambos encontramos os mesmos constituintes, sendo diferente somente os termos iniciais de cada construção. No tema, o foco são as ações para o desenvolvimento das habilidades da leitura, pertencendo a expressão inicial à classe de substantivos; no objetivo geral, a mudança fica somente pela inserção do verbo analisar, o restante da construção sintática é a mesma. Tendo como base a concepção de que o tema delimita o objeto da pesquisa e o objetivo define 0 que se pretende alcançar em relação a esse tema, observa-se neste caso uma 
escrita que, de fato, se constitui pela alteração de constituintes mínimos de um mesmo período sintático.

No que concerne à construção sintática e semântica dos objetivos geral e específicos, no primeiro o que se apresenta é uma proposição macro, que é analisar o estado atual de desenvolvimento da habilidade de leitura nos alunos. Neste caso, o esperado é que os objetivos específicos funcionem como uma espécie de detalhamento acerca do percurso que será realizado para alcançar o objetivo geral. No entanto, o que se apresenta é o seguinte: determinar os fundamentos teóricos que se relacionam com o desenvolvimento da habilidade diagnosticar de leitura nos alunos e Identificar os fatores que estão na base das dificuldades de aprendizagem da leitura por parte dos alunos da $4^{a}$ classe. $O$ primeiro objetivo específico tem um acréscimo que, como está posto, provoca incoerência, a saber, diagnosticar de leitura nos alunos. Essa expressão está descolada do restante da oração, o que dificulta a compreensão do que está sendo proposto. A parte inicial do enunciado (determinar os fundamentos teóricos que se relacionam com o desenvolvimento da habilidade) permite a hipótese de que se trata de definir os fundamentos teóricos que fundamentarão o estudo que se pretende desenvolver. Entretanto, é uma escrita genérica, que pode ser repetida infinitamente sem a implicação teórica do produtor dessa escrita.

O segundo objetivo específico apresenta uma certeza que é: Identificar os factores que estão na base das dificuldades de aprendizagem da leitura por parte dos alunos da $4^{a}$ classe. Além do aspecto genérico que se mantem, tal construção sintática remete para sentidos que levam o leitor a interpretar que 0 autor já sabe quais são as dificuldades. Assim, essa proposição específica se distancia do tema (que tem como tópico as ações para o desenvolvimento), do problema (que tem como tópico o estado do desenvolvimento) e do objetivo geral (que tem como tópico a análise do estado atual de desenvolvimento da leitura). Este objetivo específico, de fato, traz uma resposta para o geral: o estado atual do desenvolvimento da leitura é de dificuldades. Por já ser uma resposta, a ideia de pesquisa como busca de resposta perde a sua função.

Em C2M2, estão descritos o tema objetivos e problema da seguinte forma: 
C2M2

\begin{tabular}{|l|l|}
\hline Assunto & Alunos com necessidades educativas especiais \\
\hline Tema & $\begin{array}{l}\text { A atenção aos alunos com necessidades educativas especiais } \\
\text { na realidade angolana/ 2018. }\end{array}$ \\
\hline Problema & $\begin{array}{l}\text { Qual é atenção aos alunos com necessidades educativas } \\
\text { especiais da Escola Especial "15 de Setembro", município do } \\
\text { Sumbe? }\end{array}$ \\
\hline Hipótese & Não há \\
\hline gerjectivo & $\begin{array}{l}\text { Analisar o desenvolvimento do processo da atenção á } \\
\text { diversidade na educação especial, com ênfase nos alunos } \\
\text { com necessidades educativas especiais. }\end{array}$ \\
\hline $\begin{array}{l}\text { Objectivos } \\
\text { Específicos }\end{array}$ & $\begin{array}{l}\text { 1- Argumentar teóricos - metodológicos que permitem o } \\
\text { desenvolvimento do Processo da atenção à diversidades na } \\
\text { Educação Especial, com ênfase nos alunos com Necessidade } \\
\text { Educativas Especiais. } \\
\text { 2- Identificar os principais problemas que se revelam na } \\
\text { atenção á diversidades nos alunos com Necessidades } \\
\text { Educativas Especiais da Escola Especial " 15 de Setembro" } \\
\text { município do Sumbe. }\end{array}$ \\
\hline
\end{tabular}

Com relação ao tema, a hipótese é de que a expressão "a atenção"pode ser considerada sinônimo de inclusão, o que faria o enunciado ficar com a seguinte estrutura: $A$ inclusão dos alunos com necessidades educativas especiais na realidade angolana/ 2018. Com isso, fica como elemento que merece atenção a abrangência do tema: alunos com necessidades educativas especiais na realidade angolana/2018. O termo realidade angolana/2018 circunscreve um espaço (a realidade angolana) e um tempo (2018) amplos.

Nesse sentido, embora não seja essa a sua função, o problema delimita o tema, uma vez que está assim posto: Qual é atenção aos alunos com necessidades educativas especiais da Escola Especial 15 de Setembro, município do Sumbe? Neste caso, o termo marcador de tempo (ano de 2018) não aparece e a realidade angolana é delimitada para Escola Especial 15 de Setembro, município do Sumbe.

Quanto à construção sintática e semântica do tema e objetivo geral, há uma diferença na estrutura e composição do tema e do objetivo geral. Vejamos: o tema - $A$ atenção aos alunos com necessidades educativas especiais na realidade angolana/ 2018 - tem como tópico "a atenção aos alunos que apresentam necessidades educacionais especiais". Já o objetivo geral tem a seguinte proposição: Analisar o desenvolvimento do processo da 
atenção à diversidade na educação especial, com ênfase nos alunos com necessidades educativas especiais. Neste caso, entra em foco 0 desenvolvimento do processo da atenção à diversidade na educação especial. Essa primeira parte do enunciado é redundante quando consideramos que desenvolvimento e processo são termos que remetem ao mesmo objeto. Processo tem o significado corrente na língua portuguesa como andamento, desenvolvimento. Sendo uma redundância, resta observar o que segue: atenção à diversidade na educação especial. Aqui surge uma dúvida: esta parte do enunciado aponta para qual diversidade? Seria diversidade de necessidades decorrentes de diferentes tipos de deficiência? Por fim, merece atenção a última parte do período: com ênfase nos alunos com necessidades educativas especiais. Fica difícil compreender, considerando a primeira parte do período do objetivo geral, o que significa necessidades educativas especiais. Há neste caso uma tentativa de fazer uma delimitação, mas o que se tem é uma repetição que aponta para uma incompreensão acerca da semântica dos termos linguísticos que estão sendo usados.

Entre objetivo geral e os específicos, no que se refere a construção sintática e semântica, podemos afirmar que há sim uma diferença na organização estrutural que remete a diferença de sentido entre o que está sendo dito. Lembrando que o objetivo geral deve apresentar a ideia central de uma pesquisa e, principalmente, deve apontar a sua finalidade. Esta, geralmente, é iniciada pelo verbo analisar. No caso de C2M2 está assim descrito: Analisar o desenvolvimento do processo da atenção à diversidade na educação especial, com ênfase nos alunos com necessidades educativas especiais. Já os objetivos específicos devem dar maior delimitação ao tema e detalhar os percursos e processos necessários para alcançar a finalidade do objetivo geral. Na monografia em análise, dois objetivos específicos foram descritos: 1 - Argumentar teóricos - metodológicos que permitem o desenvolvimento do Processo da atenção à diversidades na Educação Especial, com ênfase nos alunos com Necessidade Educativas Especiais; 2 Identificar os principais problemas que se revelam na atenção á diversidades nos alunos com Necessidades Educativas Especiais da Escola Especial " 15 de Setembro" município do Sumbe. O primeiro apresente uma forma de 
estruturação da oração que dificultam a coerência textual; também aponta para uma ação similar à descrita nas demais monografias analisadas, que é fazer um estudo das teorias que abordam o tema. O segundo objetivo está bem delimitado quanto a sua finalidade, que é identificar os principais problemas que se revelam na atenção. Após o termo atenção, há incoerência novamente resultante da confusão que o autor faz ao usar a palavra diversidade. Fica incoerente o termo diversidade nos alunos nos alunos com Necessidades Educativas Especiais. Novamente cabe a pergunta: diversidade de quê? O que é diverso? Os alunos? As suas necessidades?

\section{A construção da metodologia de pesquisa nas monografias}

Partindo da concepção de que método é um procedimento ou caminho para alcançar determinado fim e que a finalidade de uma pesquisa é a produção de conhecimento, podemos dizer que o método científico é um conjunto de procedimentos adotados pelo pesquisador com o propósito de atingir os seus objetivos. Zinga (et al., 2019), no material de orientação do ISCED, afirmam que um projeto ou desenho de investigação é constituído pelos métodos de investigação. Nas investigações educacionais existe uma tendência a se estabelecer relações entre o método quantitativo e o método qualitativo e não assumir paradigmas exclusivos de algumas dessas tendências, tendo em conta que só a quantificação de um resultado não alcança de forma consistente a abrangência e o carácter múltiplo das pesquisas com seres humanos. Consequentemente, os autores sustentam que as concepções teóricas de métodos mais utilizadas nas investigações educacionais são:

Histórico lógico: permite analisar as diferentes etapas e a trajectória evolutiva dos antecedentes do campo de acção do objecto de investigação;

Análise e síntese: permite fazer uma análise sintética das causas do estado actual e permite o processamento da informação, assim como o apoio a estruturação da proposta; Indutivo dedutivo: possibilita trabalhar no nível do particular com os fundamentos deduzidos do estudo teórico e formular os novos juízos e generalizações que se sintetizam ao longo da investigação segundo a lógica das tarefas planificadas; 
Modelação: utiliza-se para descobrir e estudar novas relações e qualidades do objecto analisado. Realiza-se mediante uma representação simplificada da realidade, porque os modelos que se criam permitem estudar essa mesma realidade.

Hipotético dedutivo: Permite fundamentar a veracidade da afirmação; buscar argumentos que comprovam ou refutam a hipótese. Portanto, utiliza-se com demonstração ou derivação de uma ou várias afirmações (ZINGA, CAMARAZA E SAKONGO, 2019, p.40-41).

A partir dessas orientações, nos cursos de formação inicial do ISCED prevalece a concepção de que, nos métodos de nível empírico, a produção dos dados é uma etapa fundamental. É a partir disso que se considera importante o aprendizado acerca de como definir os métodos, mas principalmente que o iniciante na pesquisa compreenda esses métodos considerando o seu campo de pesquisa. Para além de saber e repetir o conceito, busca-se que saiba dizer como e porque um método ou outro está sendo utilizado. Entre os métodos empíricos mais utilizados na investigação educacional, os autores destacam a observação, o inquérito, a entrevista, o experimento, o critério de especialistas, entre outros que se combinam em função do enfoque da investigação, qualitativo ou quantitativo e dos objetivos da investigação (Zinga, et al, 2019).

C1M1 é uma monografia que apresenta as seguintes definições para as concepções de métodos e a relação destes com o objeto pesquisado.

\section{C1M1}

\begin{tabular}{|c|c|}
\hline \multicolumn{2}{|r|}{ Metodologias utilizadas } \\
\hline $\begin{array}{lrl}\text { Métodos } & \text { (de } & \text { nível teóricos, } \\
\text { empíricos } & \text { e } & \text { matemático } \\
\text { estatístico) } & & \end{array}$ & Descrição \\
\hline Indutivo - dedutivo & $\begin{array}{l}\text { Está presente ao longo do trabalho de } \\
\text { investigação para estabelecer os } \\
\text { aspectos particulares em cada } \\
\text { momento, fazer julgamento, chegar a } \\
\text { conclusão, quais temáticas e } \\
\text { concepções teóricas existentes. }\end{array}$ \\
\hline Analítico - sintético & $\begin{array}{l}\text { Utilizou-se em todas as etapas da } \\
\text { investigação para o processamento de } \\
\text { informação e investigação de critérios } \\
\text { de diferentes autores relacionados } \\
\text { com o tema de investigação. }\end{array}$ \\
\hline Inquérito & $\begin{array}{llr}\text { Para conhecer as opiniões } & \text { dos } \\
\text { professores } & \text { quanto } & \text { ao } \\
\text { desenvolvimento } & \text { da habilidade } & \text { de } \\
\text { leitura. } & & \end{array}$ \\
\hline & $\begin{array}{ll}\text { Para } & \text { constatar }\end{array}$ \\
\hline
\end{tabular}




\begin{tabular}{|l|l|}
\hline Observação & $\begin{array}{l}\text { desenvolvimento da habilidade de } \\
\text { leitura por parte dos alunos nas aulas } \\
\text { de Língua Portuguesa. }\end{array}$ \\
\hline Método Matemático & $\begin{array}{l}\text { Utilizaram-se técnica descritivas como } \\
\text { cálculo percentual, frequência de } \\
\text { tabelas, para processar a informação } \\
\text { que se obteve na entrevista e } \\
\text { questionário. }\end{array}$ \\
\hline Prova pedagógica & $\begin{array}{l}\text { Para conhecer como é } \\
\text { desenvolvimento da expressão oral } \\
\text { nos alunos da 4âa classe. }\end{array}$ \\
\hline
\end{tabular}

Em C1M1, cinco métodos foram utilizados: histórico lógico (pelo que está dito no texto da monografia, é a parte da pesquisa em que o autor buscou desenvolver uma análise do tema ao longo da história. Seria a pesquisa bibliográfica?); analítico sintético (também usado no estudo bibliográfico e da informação); indutivo-dedutivo (estudo das tarefas planificadas, da base teórica e formular juízos e generalizações); inquérito (usado de facto para a coleta de dados e ao que tudo indica pode ter sido uma técnica usada); e cálculo percentual (quantificação e seleção dos dados). Em cinco métodos, dois instrumentos foram utilizados: entrevistas e questionários. Percebe que a compreensão do pesquisador sobre o papel do método o levou a aplicá-los em cada parte da pesquisa. Ou seja, a concepção metodológica como uma lupa que orienta o todo da pesquisa não se firmou.

C2M2 é uma monografia que apresenta as seguintes definições para as concepções de métodos utilizadas e a relação destes com o objeto pesquisado.

\section{$\mathrm{C} 2 \mathrm{M} 2$}

\begin{tabular}{|l|l|}
\hline \multicolumn{2}{|c|}{ Metodologias utilizadas } \\
\hline $\begin{array}{l}\text { Métodos (de nível teóricos, empíricos e e } \\
\text { matemático - estatístico) }\end{array}$ & \multicolumn{1}{|c|}{ Descrição } \\
\hline Histórico - lógico & $\begin{array}{l}\text { Permitiu compreender com } \\
\text { profundidade a evolução histórica do } \\
\text { objecto, os fundamentos teóricos e } \\
\text { práticos relacionados com o processo } \\
\text { de Atenção as diferenças nos alunos } \\
\text { com necessidades educativas } \\
\text { especiais. }\end{array}$ \\
\hline Analítico - sintético & $\begin{array}{l}\text { Utilizou-se para processar a informação } \\
\text { consultada; analisar e resumir os } \\
\text { postulados teóricos relacionados com o } \\
\text { tema, a integração, interpretação e }\end{array}$ \\
\hline
\end{tabular}




\begin{tabular}{|c|c|}
\hline & $\begin{array}{l}\text { fundamentação do resultado dos } \\
\text { métodos e técnicas aplicada...//... }\end{array}$ \\
\hline Indutivo - dedutivo & $\begin{array}{l}\text { Permitiu o conhecimento do objecto de } \\
\text { investigação em um processo } \\
\text { integrador e coerente que vai do } \\
\text { particular ao geral, integrando-se } \\
\text { dialecticamente. }\end{array}$ \\
\hline Observação & $\begin{array}{l}\text { Para colecta de dados para conseguir } \\
\text { informações e utilizar os sentidos na } \\
\text { obtenção de determinados aspectos da } \\
\text { realidade. }\end{array}$ \\
\hline Análise documental & $\begin{array}{l}\text { Foi utilizado na pesquisa bibliográfica } \\
\text { (livros, teses, informes do INEE). }\end{array}$ \\
\hline \multicolumn{2}{|c|}{ Instrumentos utilizados } \\
\hline Inquérito & $\begin{array}{l}\text { Aplicam-se aos professores estudantes } \\
\text { e família o que permitiu conformar o } \\
\text { diagnóstico, estabelecendo médias } \\
\text { unidades que o propiciam na atenção } \\
\text { as diferenças nos alunos com } \\
\text { necessidades educativas especiais. }\end{array}$ \\
\hline Entrevista & $\begin{array}{l}\text { Aplica-se aos membros de direcção e } \\
\text { docentes em diversos momentos da } \\
\text { indagação empírica. }\end{array}$ \\
\hline
\end{tabular}

C2M2 apresenta os mesmos métodos das demais monografias analisadas e segue inclusive a mesma ordem de apresentação de cada um deles. São apontados também cincos métodos: históricos lógico, que inicia com a mesma estrutura oracional em C1M1, e também foi utilizada para analisar a evolução histórica do tema (o que permite manter a hipótese de que seria um estudo bibliográfico); analítico-sintético (pelo que está escrito utilizou em toda etapa do trabalho); indutivo-dedutivo que, conforme apontamos em C1M1, são dois métodos opostos em termo de desenvolvimento da pesquisa; também são postos como complementares e descritos como usados "para fazer julgamento do objeto de estudo; por fim, também há indicação da análise documental que, pelo que está descrito, é mobilizada pela compreensão de que a pesquisa é documental, por isso o autor de C2M2 utilizou essa concepção. Como instrumentos de pesquisa, foram utilizadas duas técnicas: o inquérito e a entrevista. Da forma como está descrita, permite a interpretação de que foram utilizados de forma complementar.

No que concerne aos métodos e técnicas escrita/descritas nas monografias, há pequenas diferenças, mas o que prevalece são semelhanças 
e repetições nas escolhas dos métodos de pesquisas. Independentemente dos objetivos e áreas de formação, verifica-se que os autores das monografias utilizaram/repetiram os seguintes métodos teóricos e empíricos: Históricológico, Analítico-sintético, Indutivo-dedutivo, Inquérito, Observação, Matemático-estatístico, Análise documental. E como instrumentos de pesquisa utilizaram: o questionário, entrevista, inquérito e a prova pedagógica. A partir disso, tendem a repetir as mesmas metodologias porque se limitam a copiarem e/ou seguirem as orientações que o material de apoio das Unidade Curricular de Metodologia de Investigação Educativa apresenta, sem confrontação de outras bibliografias e, principalmente, sem considerar as especificidades dos temas e áreas de pesquisas.

\section{Descrição e análise das citações nas monografias em estudo}

No melhor sentido do termo, citações de obras de autores diversos é a principal forma de um pesquisador estabelecer diálogos com seus pares para produzir uma escrita com densidade e conteúdo. Apropriar-se criticamente das palavras de um autor é uma forma de promover a circularidade do conhecimento entre pesquisadores. Este gesto do pesquisador é inerente ao ato de fazer pesquisa. É nesta perspectiva que Rolon et al. sustentam que

\footnotetext{
É por meio da pesquisa bibliográfica, uma das etapas do projecto de pesquisa, que se realiza o levantamento do referencial teórico com o qual sustentamos, refutamos ou analisamos o que circunscreve o objecto investigado. $O$ texto de um autor é, portanto, uma fonte documental com a qual devemos adoptar critérios rigorosos ao mencioná-lo em nosso discurso académico, o que implica seguir as normas de pesquisa científica, especialmente, a fim de preservar a propriedade intelectual, garantida pelo direito autoral. (Rolon, et al, 2018, p.48).
}

Além disso, ao adotar como modelo de citação as normas da Associação dos Psicólogos Americanos (APA), recomendada no regulamento de trabalhos de fim de curso do ISCED, fica estabelecido quatro modelos básicos de citações: citação direta (a transcrição literal do texto fonte), citação indireta (trancrição dos conceitos do autor consultado, mas escrito sem ser uma transcrição literal); citação de citação (é a citação de uma obra a partir do que 
foi citado por um autor comentador, não da leitura do texto fonte); citação de fonte informal (citação de fontes não publicadas, tais como e-mails, apresentações de trabalhos em eventos etc.) (ROLON, et al., 2018)

Nesses quatro tipos de citação estão descritos como a palavra do outro deve ser referenciada dentro de um texto e, sobretudo, indicam também como deve ser demarcada a relação entre autor citado e autor citante. Em todas, há que se ter o cuidado para não ocorrer a apropriação indevida da palavra alheia. A seguir, apresentamos o quadro com fragmentos de citações retiradas das monografias em estudo, para analisarmos e refletirmos sobre como os autores das monografias mobilizam as palavras de outros autores.

\section{C1M1}

\begin{tabular}{|c|c|}
\hline № & $\mathbf{s}$ \\
\hline $1^{\mathrm{a}}$ & $\begin{array}{l}\text { Segundo Frank Parsons (1909) citado por Rodriguez Moreno (1987) a } \\
\text { orientação profissional exige três actuações: Análise da pessoa para } \\
\text { conhecer as capacidades, interesses e temperamento; análise da tarefa } \\
\text { para que o orientador conheça os requisitos, oportunidades de vários } \\
\text { tipos de trabalho; a comparação conjunta de todos os tipos de análise } \\
\text { para raciocinar as relações entre os tipos de dados. (p.21). }\end{array}$ \\
\hline $2^{a}$ & $\begin{array}{l}\text { López Urquíz \& Sola Marínez (2002: 14) falam que a orientação educativa } \\
\text { tem de partir de uma relação entre o orientador e o orientado e que para } \\
\text { eleger a vocação há que nos basear numa concepção orientadora e nos } \\
\text { "princípios de prevenção" e "desenvolvimento e intervenção social". Este } \\
\text { princípio de prevenção visa reduzir os obstáculos mas não eliminá- los. }\end{array}$ \\
\hline $3^{a}$ & $\begin{array}{l}\text { CLAPARED, aptidão é todo carácter psíquico ou físico, considerado sob o } \\
\text { ângulo do rendimento. }\end{array}$ \\
\hline $4^{\underline{a}}$ & $\begin{array}{l}\text { Um professor influi pa } \\
\text { pode dizer até aonde }\end{array}$ \\
\hline $5^{a}$ & $\begin{array}{l}\text { Segundo Bohoslavky (1977): "escolher é decidir entre uma série de } \\
\text { opções a que parece melhor naquele momento e fazer dele um projecto } \\
\text { de vida que vai realizar e esse é posicionamento filosófico e ético". }\end{array}$ \\
\hline $6^{\mathrm{a}}$ & $\begin{array}{l}\text { A posição do indivíduo no capitalismo não é mais determinada, pelos } \\
\text { laços de sangue, esta posição é conquistada pelo indivíduo segundo } \\
\text { esforço que despende para alcançar esta posição. Se antes esta posição } \\
\text { era entendida em função das leis naturais referendadas em função das } \\
\text { leis divinas, agora, ao contrário, o indivíduo pode tudo, desde que lute, } \\
\text { estude, trabalhe, se esforce, e também porque não? Seja um pouco } \\
\text { quinhoando pela sorte (BOCK 1989, pag.15). }\end{array}$ \\
\hline $7^{a}$ & $\begin{array}{l}\text { Ser cidadão significa ter direito ao trabalho humanizado e a realização } \\
\text { como sujeito socioeconómico (Antoncich e Ceschin, } 1989 \text { apud Silva e }\end{array}$ \\
\hline
\end{tabular}

Em C1M1, no primeiro caso, o autor faz uma citação da citação, utilizando os nomes completos dos autores citados, quando usaria apenas os sobrenomes e faz referências ao ano de publicação e a página conforme 
recomenda a regra. $\mathrm{Na}$ segunda citação, o autor faz uma citação direta curta e utiliza os nomes completos dos autores citados separando com (\&), quando seria apenas os sobrenomes e separados com a letra (e), uma vez que não está dentro dos parênteses, o ano e o número de página estão separados com (:) quando seria (p.). A terceira citação, pelo que está descrito, é confusa porque encontramos apenas o sobrenome do autor, sem o ano, nem página da obra consultada, o que deixa o leitor sem compreender se estamos diante de uma citação direta curta ou indireta. O mesmo acontece na quarta citação, que tem o sobrenome sem o ano nem a página, o que causa dúvidas se estamos perante que tipo de citação. Na quinta, é uma citação direta curta, pois os dizeres do autor citado está entre aspas, embora encontremos o sobrenome e o ano da obra citada sem o número da página. A sexta citação direta e longa. No entanto, o autor não cumpre com a orientação técnica exigidas nesses tipos de citações (citações com mais de 40 palavras, devem ser apresentadas em um bloco de texto separado sem aspas. Inicie essa citação em um bloco com recuo de $1,25 \mathrm{~cm}$ da margem esquerda, espaçamento simples nos blocos de citação directa e no final informe a fonte citada e o número da página ou do parágrafo entre parênteses depois do ponto final, tamanho de letra 10 ou 11); ainda, encontra-se entre parênteses o nome do autor, o ano e página citada. Na abreviatura da página (p.), o autor fez (pag.). A sétima é uma citação da citação, tem os sobrenomes dos autores citados e dos que citam separados da palavra latina apud quando seria "citado por" e o ano da publicação, faltando o número da página.

\section{C2M2}

\begin{tabular}{|c|l|}
\hline № & \multicolumn{1}{c|}{ Descrição dos fragmentos } \\
\hline $\mathbf{1}^{\mathbf{a}}$ & $\begin{array}{l}\text { Segundo Gamboa J, 2016 define a atenção como um processo cognitivo pelo } \\
\text { qual o intelecto focaliza e selecciona o estímulo. }\end{array}$ \\
\hline $\mathbf{2}^{\mathbf{a}}$ & $\begin{array}{l}\text { Correia (19993, 1997, 20003) diz ao conceito de N.E.E, afirmando que ele se } \\
\text { aplica a criança e adolescentes com problemas sensoriais, físicos, intelectuais } \\
\text { e emocionais e, também, com dificuldades de aprendizagens especificas...//... }\end{array}$ \\
\hline $\mathbf{3}^{\mathbf{a}}$ & $\begin{array}{l}\text { A diferença entre as pessoas é um valor e não um defeito. Não existem duas } \\
\text { flores iguais, o mais formoso na natureza e no ser humano e a diversidade. } \\
\text { MIGUEL, L.M. citado por Vilma V, (2017,p,7). }\end{array}$ \\
\hline $\mathbf{4}^{\mathbf{a}}$ & $\begin{array}{l}\text { Outrossim no entender de Correia (1991, 1997), Kauffman e Lloid (1996), } \\
\text { Hallahan et. al., (2005), caracterizam este problema por uma discrepância } \\
\text { acentuada entre o potencial estimado e a sua realização escolar...//... }\end{array}$ \\
\hline
\end{tabular}


5 $\quad$ Roldão (1999) sublinha também a importância de o profissional de educação "dominar um conjunto de saberes, que incluem conhecimentos teóricos e práticos, competências e capacidades específicas (p.112)".

Em C2M2, na primeira citação, pelo que está escrito na monografia, trata-se de uma citação indireta, tem o sobrenome que não foi separado com a (,) e o ano não está entre parênteses. Na segunda citação, há o sobrenome e o ano da publicação da obra, mas não encontramos o número de página, o que nos leva a hipotetizar que se trata de uma citação indireta. A terceira é uma citação da citação, tem os sobrenomes dos autores da obra citada, mas acresce a abreviatura do restante dos nomes, quando não seria necessário. $\mathrm{Na}$ quarta citação, temos os anos sem os números de páginas das obras consultadas, o que nos leva a levantar a hipótese de que se trata de uma citação indireta. Na quinta citação, o autor da monografia faz uma citação direta curta com todos os requisitos necessários para a execução dela.

\section{CONSIDERAÇÕES FINAIS}

Em gestos de apresentação das considerações finais, é fundamental voltar ao objetivo geral que norteou a escrita deste artigo: fazer uma descrição de produção escritas de alunos de cursos de licenciaturas do ISCED CS, visando descrever e analisar a construção desses textos. A partir das análises desenvolvidas, é possível afirmar que a seleção, delimitação dos temas, problemas e objetivos de uma pesquisa são elementos fundamentais e determinantes para a consecução dos resultados, mas, principalmente, para a formação do pesquisador iniciante. Esses elementos precisam ser bem planificados ou pensados para o desencadeamento de uma pesquisa. Ao que se refere às monografias analisadas, encontramos similaridades/repetições na formação e formulação dos temas, problemas e objetivos das pesquisas.

Consequentemente, analisando os temas das monografias, vemos que há muitas semelhanças em termos de construção e formulação sintática e semântica. Nas diferentes áreas de conhecimento que englobam o ISCED Ciências de Educação, Ciências Sociais, Ciências Exatas e Ciências da Natureza - constatou-se pouca diferença na maneira de escrever o texto 
monográfico, ou seja, independentemente do regulamento que orienta a investigação ser o mesmo, comumente há distinção na forma de produção da escrita nas diferentes áreas do saber, o que não se verificou nas monografias analisadas.

É possível concluir ainda que o tipo de pesquisa determina a metodologia a ser aplicada. Numa pesquisa não se deve utilizar vários métodos, principalmente quando se trata de trabalho inicial como é o caso da monografia (como trabalho de conclusão de curso na graduação ou licenciatura), o comum é a opção por um método quando se trata de trabalhos principiantes em investigação científica. Caso haja necessidade de uma convivência de métodos, essa relação precisa ser compreendida, explicada e, principalmente, precisa ser considerada necessária para se alcançar o objetivo de pesquisa.

Em consulta ao banco de textos online do projecto "Leitura e escrita no Brasil, Honduras, Angola e Chile: formação na universidade contemporânea e (re)produção de conhecimento", foi possível constatar que, no que diz respeito à definição do método de pesquisa, o comum é se trabalhar com o qualitativo, o quantitativo e/ou as chamadas pesquisas quanti/quanli, que envolvem os dois métodos. Dentro dessa definição macro, o que se observou é que são feitas outras subdivisões do tipo: pesquisa qualitativa bibliográfica; pesquisa qualitativa histórica; pesquisa quantitativa descritiva e assim por diante. Essas definições orientam a escolha dos instrumentos, uma vez que a literatura sobre o assunto demonstra que, para cada método, há instrumentos considerados adequados. Para as pesquisas qualitativas histórica, estudos de casos, o que se constatou na análise dos dados do projecto, é a predominância do uso da entrevista, de dados documentais e assim sucessivamente. Cabe destacar que a definição dos instrumentos é sempre orietanda pelo método e, principalmente, pelos objetivos (BARBOSA, 2018).

Adicionalmente, uma pesquisa indutiva é diferente de uma dedutiva; inclusive possuem perspectivas filosóficas muito diferentes, os pontos de partidas de cada uma são opostos em tornos de desenvolvimento da pesquisa. Esses dois métodos são considerados racionais e muitas vezes se opõem às bases filosóficas do método qualitativo, por exemplo. Segundo Leite (2008) 
Diz-se dedutivo o método cuja construção científica parte do raciocínio geral para o particular, do universal ao individual. Diz-se que o raciocino dedutivo pode ligar leis que foram elaboradas separadamente e conseguir suas confirmações. É quase que exclusivamente o método utilizado pelas ciências exatas, sobretudo pela matemática. $O$ método indutivo é uma construção mental, científica, racional que parte de variáveis particulares, chegando às gerais. Parte-se de um fenómeno para a lei geral ou da observação de dois eventos ou casos, experimentados, para se descobrir sua relação e generalizá-la como lei [...]. (LEITE, 2008, p. 93).

Nos trabalhos analisados, esses métodos são postos todos numa mesma pesquisa, sem a compreensão da relação, das diferenças que precisam ser estabelecidas entre eles. Isso é problemático porque é importante, principalmente para o pesquisador iniciante, definir e compreender a perspectiva filosófica mobilizada para desenvolver a pesquisa, ou da perspectiva filosófica indutiva ou dedutiva e não por ambas como complementares. "A utilização de um ou de outro método depende de muitos fatores: da natureza do objeto que pretendemos pesquisar, dos recursos materiais disponíveis, do nível de abrangência do estudo, e, sobretudo, da inspiração filosófica do pesquisador" (PRODANOV; FREITAS, 2013, p.27).

Portanto, nas monografias analisadas, os autores, ao se limitarem a realização da cópia de um conjunto de métodos, encaixando-os aos seus temas de investigação, nos leva a inferir que não fazem confrontações de outras bibliografias, tão pouco procuram fazer enquadramentos dos métodos aos tipos de pesquisas e objetos que cada um pretende alcançar. Ainda, há uma repetição na redação das definições dos métodos, vê-se um manuseio, no sentido de deixar maior ou menor as frases, com vista a adequar o já escrito em algum lugar ao tema da pesquisa.

Nisto, independentemente de fazer o mesmo tipo de pesquisa ou seguir o mesmo guião orientador que cada instituição adota, não se pode fazer a mesma coisa, uma vez que cada pesquisa é uma pesquisa e ainda há as diferenças de área de conhecimento científico. Ciências Naturais, Sociais e Humanas ou Exatas têm as suas particularidades e especificidades que devem presenciar-se durante a investigação no sentido geral e, em particular, nas escolhas dos métodos para aplicação. 
Outra realidade a ser considerada é que, no sentido geral, as citações nas monografias não são feitas de maneira a demonstrarem que os autores mantêm um constante diálogo com os autores das obras consultadas, mas são também repetições dos posicionamentos dos outros sem interagirem, tão pouco sustentarem ou fundamentarem as citações. Os autores das monografias demonstram que estão apenas cumprindo uma formalidade ou orientação técnica de que é preciso fazer citações. Tanto que, em vários casos, não põem entre aspas os dizeres do autor que citam, nem põem os números das páginas das obras consultadas, embora seja uma citação direta, outros fazem citações inadequadas, o que deixa as monografias com algumas insuficiências.

Como resultado das descrições sobre como estão escritas as monografias, podemos concluir que a construção textual apresentada acarreta uma escrita muito mais repetitiva do que criativa. Portanto, cabe destacar que, embora haja uma estrutura de elaboração de TFC com todos os elementos necessários para uma monografia de acordo com os parâmetros estabelecidos pelo ISCED, a escrita resultante desse percurso mostra forte indícios das dificuldades encontradas pelos concluinte dos cursos produzirem um texto próprio. As repetições apontam para incompreensões sobre o que seja fazer uma pesquisa, sobre o que seja escrever um tema, um problema, objetivos, base teórica e metodologias; não só, as repetições demonstram o não acesso aos conhecimentos básicos necessários à formação inicial de um pesquisador.

\section{REFERÊNCIAS}

BARBOSA, M. V. Leitura e escrita no Brasil, Honduras, Angola e Chile: formação na universidade contemporânea e (re)produção de conhecimento. Projeto de Pesquisa, 2018.

Decreto Executivo-Lei no 32/20, de 12 de Agosto. Lei de Base do Sistema de Educação e Ensino, Angola, 2020.

De Sousa, L. L.; Sakongo, A. J. O. F; António, M. C. Ações desenvolvidas pelo Instituto Superior de Ciências da Educação do Cuanza Sul (ISCED CS) em conjunto com as universidades brasileiras parceiras. 2019. 
LEITE, T. F. Metodologia Científica, métodos e técnicas de pesquisa (monografias, Dissertações, Teses e Livros). São Paulo: Editora Ideias \& Letras, 2008.

RIBEIRO, H.; CUNHA, J. M.; PEREIRA, L.; CASTRO, S. Gramática Moderna de Língua Portuguesa. Lisboa: Escolar Editora, 2012.

ROLON, R. B. B. (Org) et al. Como escrever a pesquisa: normas técnicas, metodologia e guia do trabalho académico. Manaus: Editora UEA, 2018.

SEVERINO, A.J. Metodologia do Trabalho Científico. São Paulo: Cortez: Editora, Brasil, 2007.

Universidade Katyavala Bwila. Relatório de actividades e contas do ano de 2018.Disponível em: http://www.ukb.ed.ao. Acesso em: 20 fev. 2021.

ZINGA, A.; CAMARAZA, C.A.; SAKONGO, A. De J. De O. F. Texto de apoio da unidade curricular de Metodologia de Investigação Educativa. ISCED CS, 2019. 